\title{
Risk factors for undernutrition of young children in a rural area of South Africa
}

\author{
Mickey Chopra* \\ School of Public Health, University of the Western Cape, Private Bag x17, Bellville 7535, Western Cape, South Africa
}

Submitted 5 November 2002: Accepted 1 April 2003

\begin{abstract}
Objective: To identify the factors associated with childhood undernutrition.

Design: Cross-sectional survey.

Setting: Hlabisa health district in KwaZulu/Natal, South Africa.

Subjects: Eight hundred and sixty-eight children aged 3-59 months.

Methods: Questionnaire survey and anthropometric survey of 516 random households with children in the health district. Multivariate analysis took into account the hierarchical relationships between the proposed risk factors. This conceptual model was built up during qualitative studies and with reference to international research in this area.

Results: The mean $Z$-scores for weight-for-age and height-for-age were $-0.52(95 \%$ confidence interval (CI) -0.44 to -0.60$)$ and -1.25 (95\% CI -1.15 to -1.35$)$, respectively. Of the children, 26.3\% (95\% CI 23.3-29.3\%) were stunted, 12.0\% (95\% CI 9.8-4.2\%) were underweight-for-age (UWFA) and only $1.3 \%$ were wasted. Migrant father, mother's education, literate mother, whether the house was made of traditional materials, the presence of a toilet, whether the last child was breast-fed, duration of breast-feeding and birth weight were found to be significantly related to UWFA, the latter with an odds ratio of more than eight.

Conclusion: While there are individual health and feeding behaviours that need to be addressed, this study has also uncovered the maternal and socio-economic factors which present an array of constraints in the social environment shaping the infant feeding and caring practices employed by women. For the full potential of nutrition promotion activities to be realised, there is a need to address some of these 'deeper' constraints.
\end{abstract}

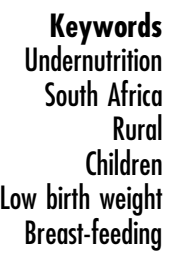

It has been estimated that malnutrition underlies more than half of all infant and child mortality in sub-Saharan Africa ${ }^{1}$. It is also associated with reduced future scholastic achievement and earning capacity ${ }^{2,3}$. In South Africa about 2.3 million children suffer from undernutrition ${ }^{4}$. The South African Government has made the amelioration of infant and child malnutrition a priority.

Traditionally, nutrition interventions in South Africa have consisted of feeding schemes based at clinics, crèches, schools or soup kitchens. However, evaluations of these programmes have been disappointing ${ }^{5,6}$. It has been argued that these types of programme, through their focus on the poor and already malnourished, fail to address the wider social and economic causes of undernutrition. This is especially important in the South African setting, with its history of apartheid and its presentday legacy of gross inequalities.

The identification of important causal factors in particular settings is one of the most important steps in the development of more appropriate and effective nutrition programmes ${ }^{7}$.
The aim of this paper to is present the findings of the baseline survey of a randomised control trial investigating the effect of a community-based growth monitoring intervention. It describes the relationship between various socio-economic, environmental and health factors and the nutritional status of pre-school children in a rural health district in South Africa. The results of this study should provide policy-makers and nutrition managers with important information for nutrition planning in rural areas of South Africa.

\section{Methods}

\section{Setting}

Hlabisa health district is situated on the north coast of KwaZulu/Natal, $200 \mathrm{~km}$ north of Durban. The population of approximately 200000 is almost exclusively black and rural, living largely in scattered kraals, and depends mainly upon migrant labour, pensions and subsistence farming for income and food. The district employs 72 Community Health Workers (CHWs) who cover about a third 
of the health district. The CHWs are local women who have been chosen by the community and are paid by the local authority to work 16 days a month. On average they cover about 100 households each.

\section{Sampling procedure}

Each CHW was assigned a unique number and 12 numbers were selected through the use of a random numbers table. The chosen study areas were visited before the start of the study. Permission was obtained from the local traditional leader (Induna) and community meetings were held to describe the study and gain local support.

The study sample consisted of households with children aged 3-59 months who resided in the chosen CHW area for $>3$ months in the year. Children aged $<3$ months and those with severe congenital problems were excluded because of the significant effect of prenatal factors on their growth.

Five local, Zulu-speaking college students were trained in the administration of the questionnaire. CHWs have lists of all households with children aged $<6$ years and all of these were visited. The questionnaire was filled in during an interview with the main carer in the household. If the carer was absent, the household was revisited for a further two occasions.

\section{Questionnaire}

The questionnaire was developed after participatory exercises and focus groups had clarified local risk factors and markers for poverty and households with undernourished children. The questionnaire was piloted and revised a number of times before being finalised. Children's date of birth, birth weight and immunisation status were taken from the Road to Health Card (this is the local growth card) and when this was not present the date of birth was taken from the birth certificate; if this was not present it was requested from the mother. In $88 \%$ of cases the birth date was taken from the card, in $8 \%$ from birth certificates and the remainder from the carer. After completing the interview the carer was asked to attend a central weighing and measuring point the following week with the child.

\section{Weighing and measuring}

Two dietetic students conducted the anthropometric measurements. An experienced anthropometrist supervised the training, weighing and measuring of all children. She also assessed for severe congenital abnormalities. Salter weighing scales were used and calibrated before and after each session. The children were weighed with only minimum clothing (diapers for babies and underclothes for older children) and the average of two readings was taken.

Heights were measured on height boards that were constructed for the survey. Care was taken to ensure that the children were standing upright with feet flat and firmly against the wall; one researcher ensured that the child was upright whilst the other measured the height. Children aged $<2$ years were measured supine.

A supervisor randomly checked these measurements. Weights were measured to the nearest $0.01 \mathrm{~kg}$ and height to the nearest $0.1 \mathrm{~cm}$. Reliability was ensured during the training of the two field workers until they had over $90 \%$ inter-rater reliability for at least two independent, consecutive measurements.

\section{Analysis}

All data were initially recorded on microcomputers, and the data cleaned and crudely analysed using Epi-Info 5.9 (Centers for Disease Control and Prevention, Atlanta, GA, USA). Anthropometric measurements were converted to three indexes: height-for-age, weight-for-age and weightfor-height. These indexes were then converted into standard deviation (SD) scores (Z-scores) relative to the international reference population to standardise the distribution $^{8}$. A child was defined as wasted if his/her weight-for-height was below - 2SD from the reference value. Similarly, stunting and underweight-for-age (UWFA) were defined as children below - 2SD of the reference median value for height-for-age and weight-forage, respectively ( $Z$-score $<-2$ in each case).

The multivariate analysis was performed with STATA version 5 (Stata Corp., College Station, TX, USA). Odds ratios and their 95\% confidence intervals (CIs) were calculated using conditional logistic regression. Statistical significance was assessed through the likelihood ratio test.

The multivariate analysis took into account the hierarchical relationships between the proposed risk factors? ${ }^{9}$. This conceptual model was built up during the qualitative studies and with reference to international research in this area. According to this model (Fig. 1), socio-economic variables may determine, directly or indirectly, all variables being studied except the child's age and gender. The next level comprises the environmental variables, which are partly determined by socioeconomic status. The third level consists of the immediate nutritional causes such as birth weight and feeding beliefs and practices.

In the first step of the multivariate analyses, the age and gender variables were entered. Next all socio-economic variables were added including those that were not significant in the crude analysis. The crude odds ratios were compared with the adjusted ones. If there was a clear association - including a dose-response pattern with variables with three or more categories and there was statistical significance - then the variable was retained. To this new model the next level of variables was then added, and a similar procedure was repeated for all levels.

The odds ratios presented in the multivariate analyses were not derived from the full model with all of the variables, but from the equation corresponding to the level in which the risk factor was first entered. This avoids the 


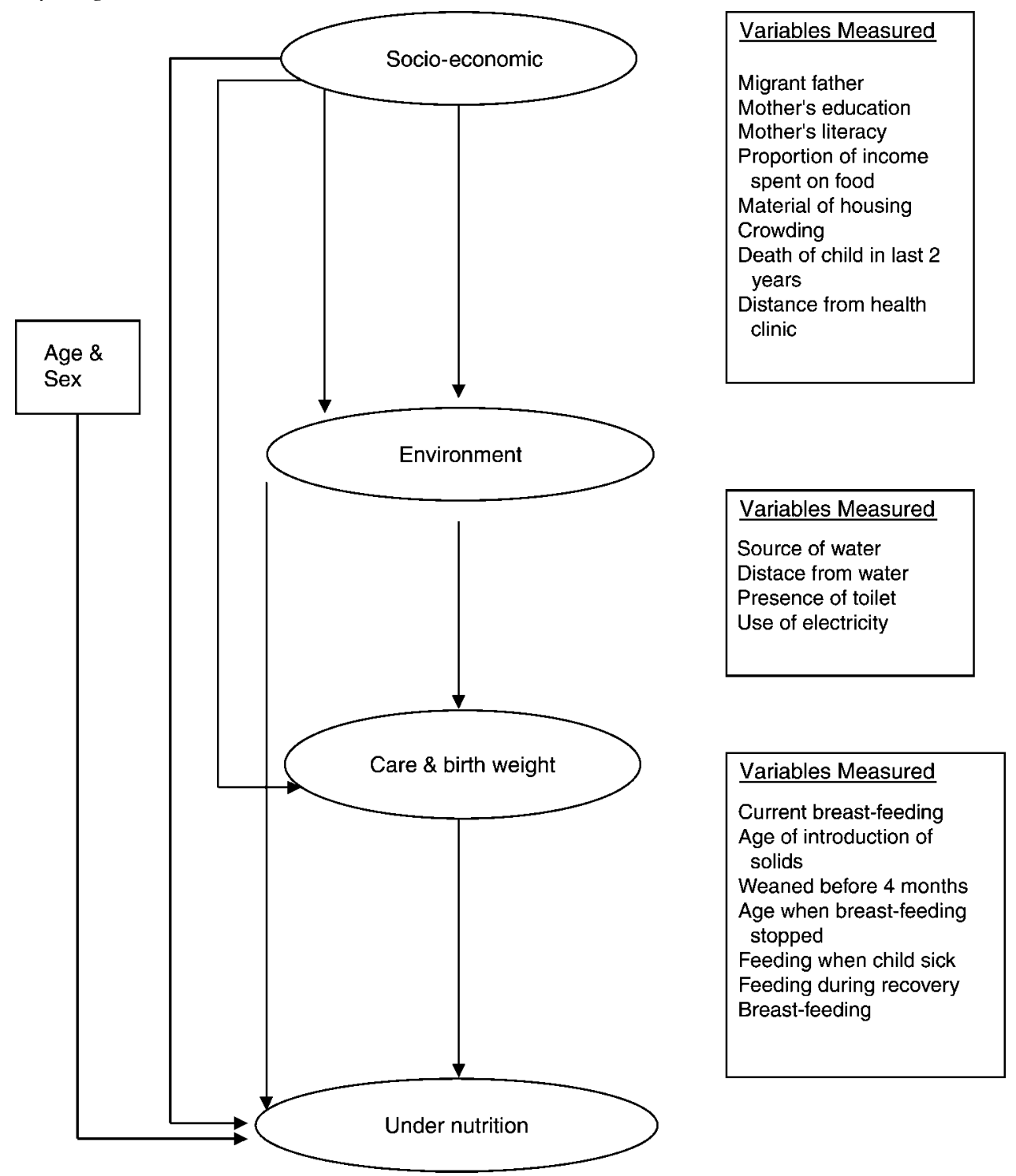

Fig. 1 Conceptual framework of the multivariate analysis, taking into account the hierarchical relationships between the proposed risk factors

possibility that mediating variables take away some of the explanatory power of the more distant determinants. For example, part of the effect of income on the nutritional status of the child may be mediated through better sanitation. The overall effect of income should be examined in a model in which sanitation variables were not included, otherwise its role would be underestimated 9 .

\section{Results}

Five hundred and sixteen households ( $97 \%$ of total) were interviewed and 922 children were listed. Of these, 868 (94\%) were taken to the weighing station and weighed and measured. The others refused to have their children measured (nine (1\%)) or the children were out of the area at the time of weighing (15 (1.5\%)) or their ages were unknown $(30(3.5 \%))$. Of those children who were brought to the weighing point, five $(0.5 \%)$ were excluded because they were suffering from congenital problems likely to greatly influence their growth and a further 15 (1.5\%) were excluded because they were of the wrong age.

The mean age of the children was 29.0 months (range 3-59 months, SD 16.3 months). There were roughly equal proportions of boys and girls ( $49 \%$ vs. $51 \%$ ).

\section{Characteristics of the population}

Table 1 shows the main socio-economic and environmental characteristics. In all cases the toilets were either ventilated pit latrines ( $44 \%$ of toilets) or simple pit latrines. Respondents reported various sources of income, of which remittances ( $40 \%$ of households), pensions (25\%) and sewing (15\%) were the most important.

Only $57 \%$ of respondents stated that it was the mother who could decide how much money was spent on food; in 
Table 1 Distribution of key socio-economic factors

\begin{tabular}{lc}
\hline Variable & Prevalence (\%) \\
\hline Migrant father & \\
Father present every day & 42 \\
Father present once a week & 14 \\
Father present once a month & 25 \\
Father never present & 19 \\
Mother's education & \\
$>5$ years & 27 \\
$<5$ years & 51 \\
Nil & 22 \\
Mother's literacy & \\
Can read a sentence in Zulu & 77 \\
Cannot read a sentence in Zulu & 23 \\
Daytime carer of child & \\
Mother & 41 \\
Grandmother & 39 \\
Neighbour & 6 \\
Sibling & 5 \\
Other & 9 \\
Proportion of income spent on food & \\
<50\% & 17 \\
$50-75 \%$ & 48 \\
$>75 \%$ & 35 \\
House made of traditional material & \\
Yes & 30 \\
No & 70 \\
Source of water & \\
Well & 11 \\
Pipe/pump & 36 \\
River & 53 \\
Presence of toilet & \\
Yes & 66 \\
No & 33 \\
Use of electricity & \\
Yes & 48 \\
No & 52 \\
\hline & \\
\hline & \\
\hline & \\
\hline
\end{tabular}

$23 \%$ of cases it was the grandmother who decided and in $16 \%$ of households it was the father who made the decision.

\section{Health knowledge and behaviour}

Most mothers (86\%) had breast-fed their last child but a majority had introduced either fluids (71\%) or solids (55\%) before 4 months. Nearly two-thirds of carers (64\%) reported reducing feeding during illness and over a quarter (27\%) stated that they did not increase frequency of feeding after the child had an episode of illness. More seriously, nearly one in 10 carers reported stopping feeding during illness and 8\% actually decreased the amount of food given after an illness.

Eighty-one per cent of households reported having to travel for more than one hour to reach a healthcare facility. Nearly half (49\%) of the respondents had delivered at least one child at home and $11 \%$ had delivered two children at home; $12 \%$ of carers reported that they had never delivered in hospital.

However, 90\% of households were able to produce a Road to Health Card, and $97 \%$ and $80 \%$ of eligible children had tuberculosis and measles vaccination completed, respectively.

\section{Anthropometric measurements}

The mean $Z$-scores for weight-for-age and height-for-age were -0.52 (95\% CI -0.44 to -0.60$)$ and -1.25 (95\% CI -1.15 to -1.35 ), respectively. Of children, $26.3 \%$ (95\% CI 23.3-29.3\%) were stunted, $12.0 \%$ (95\% CI 9.8-14.2\%) were UWFA and only $1.3 \%$ were wasted. Six hundred and thirty-four children (75\%) had their birth weight recorded on the health card; the mean birth weight was 3.16 (SD $0.53) \mathrm{kg}$ and $16.3 \%$ had birth weight below $2500 \mathrm{~g}$. Figure 2 presents the mean $Z$-scores for different age groups.

\section{Risk factors associated with undernutrition}

Table 2 shows the risk factors found to be significantly related to UWFA after multivariate analysis. In the first model, all socio-economic variables were added with the age and sex variables. Migrant father, mother's education, literate mother and whether the house was made of traditional materials were retained because they showed a significant association with the outcome of UWFA. Only the presence of a toilet was significantly related to UWFA of all the environmental variables and this was retained in the model. Finally, variables related to care and birth

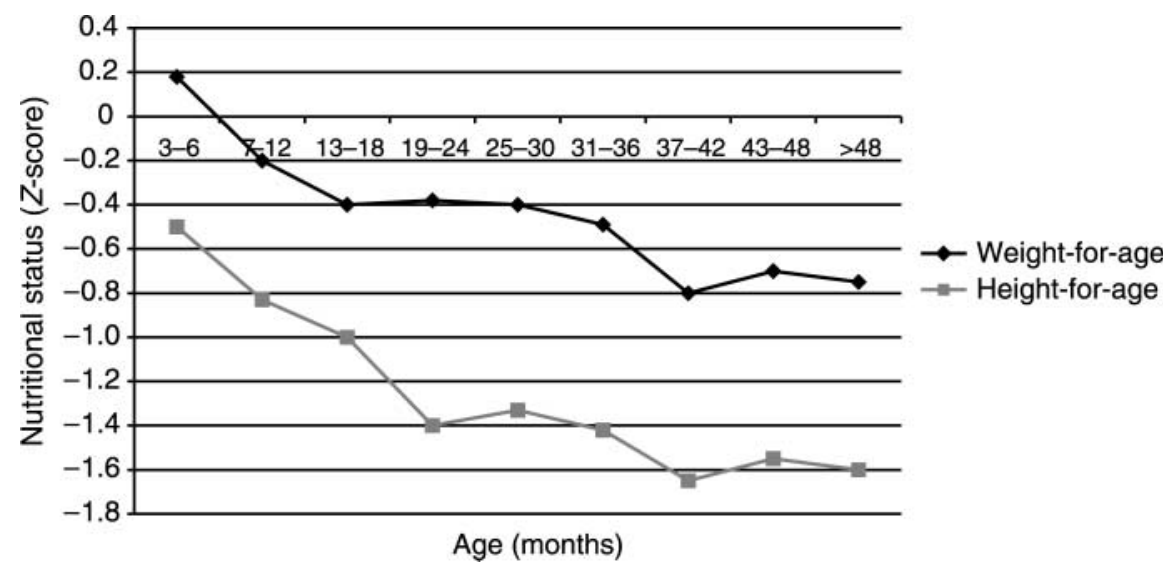

Fig. 2 Nutritional status according to age 
Table 2 Risk factors for underweight-for-age

\begin{tabular}{|c|c|c|c|}
\hline Risk factor & Odds ratio & $\begin{array}{l}\text { 95\% confidence } \\
\text { interval }^{*}\end{array}$ & $P$-value* \\
\hline \multicolumn{4}{|l|}{ Migrant father } \\
\hline Father present $>$ once per week & $1.00 \dagger$ & & \\
\hline Father present < once per week & 1.62 & $1.02-2.59$ & 0.05 \\
\hline \multicolumn{4}{|l|}{ Mother's literacy } \\
\hline Cannot read a sentence & $1.00 \dagger$ & & \\
\hline Can read a sentence & 0.57 & $0.33-1.00$ & 0.05 \\
\hline \multicolumn{4}{|l|}{ Mother's education } \\
\hline$<5$ years & $1.00 \dagger$ & & \\
\hline$>5$ years & 0.58 & $0.33-0.95$ & 0.04 \\
\hline $\begin{array}{l}\text { House made of traditional material } \\
\text { No }\end{array}$ & & & \\
\hline No & $1.00 \dagger$ & & \\
\hline Yes & 2.73 & $1.21-6.14$ & 0.02 \\
\hline \multicolumn{4}{|l|}{ Presence of toilet } \\
\hline Yes & 1.00 & & \\
\hline No & 2.04 & $1.25-3.35$ & 0.004 \\
\hline \multicolumn{4}{|l|}{ Breast-fed last child } \\
\hline No & 1.00 & & \\
\hline Yes & 0.35 & $0.12-0.96$ & $<0.001$ \\
\hline \multicolumn{4}{|c|}{ Age when breast-feeding stopped (months) } \\
\hline$<1$ & 1.00 & & \\
\hline $1-4$ & 0.08 & $0.01-0.70$ & \\
\hline $4-12$ & 0.08 & $0.01-0.45$ & \\
\hline $12-24$ & 0.09 & $0.02-0.52$ & \\
\hline$>24$ & 0.14 & $0.03-0.93$ & 0.02 \\
\hline \multicolumn{4}{|l|}{ Birth weight } \\
\hline$>2500 \mathrm{~g}$ & $1.00 \ddagger$ & & \\
\hline$<2500 \mathrm{~g}$ & 8.30 & $4.35-15.8$ & $<0.001$ \\
\hline
\end{tabular}

weight were added and of these whether the last child was breast-fed, duration of breast-feeding and birth weight were found to be significant, the latter with an odds ratio of more than eight.

Low birth weight is also the most important risk factor for stunting (Table 3). Literacy of the mother and duration of breast-feeding were not significantly related to stunting in the multivariate analysis. Whether or not the daytime carer was the mother was significant in the bivariate analysis, but this did not hold when other socio-economic, environmental and care variables were controlled for.

\section{Discussion}

The pattern of low levels of acute undernutrition (i.e. wasting) but high levels of chronic undernutrition as manifested by the high levels of stunting is similar to that found in other local and national surveys in South Africa $^{4,10,11}$. Many families suffer from poverty as reflected by the few people in waged employment, heavy reliance upon remittance and pensions and the relatively high levels of spending on food. This is accentuated by the poor infrastructure, such as lack of access to water and health care, and the high number of fathers absent from the household. The risk factors for stunting and underweight - absence of father, material of house, absence of toilet, distance from clinic, no breast-feeding and low birth weight - reflect the socio-economic status of the household and maternal factors. These findings have important implications for nutritional interventions in South Africa.

There has been increasing appreciation of the possibility that the aetiology of stunting may be different to that of acute wasting ${ }^{12}$. Countries such as Jordan have witnessed a dramatic fall in the prevalence of wasting due to vastly improved health service delivery and identification and treatment of acutely malnourished children, whereas the prevalence of stunting has remained at high levels $^{13}$. This experience reflects the biological and epidemiological evidence, which suggests that stunting is the effect of chronic exposure to adverse conditions, national and even international factors in the aetiology of chronic undernutrition.

In this area, children who start off with low birth weight (i.e. below $2500 \mathrm{~g}$ ) are over eight times more likely to be UWFA and five times more likely to be stunted. This is consistent with findings from other studies ${ }^{12,13}$. Poor maternal nutrition has been shown to be one of the major causal determinants of intrauterine growth retardation (IUGR) in both developed and developing countries ${ }^{14}$. Studies of nutrition interventions with balanced energy and protein supplements in pregnancy to reduce low birth weight have been disappointing ${ }^{15}$. However, women randomised to receive a daily supplementation with 
Table 3 Risk factors for stunting

\begin{tabular}{|c|c|c|c|}
\hline Risk factor & Odds ratio & $\begin{array}{l}95 \% \text { confidence } \\
\text { interval }^{*}\end{array}$ & $P$-value* \\
\hline \multicolumn{4}{|l|}{ Migrant father } \\
\hline Father present $>$ once per week & $1.00 \dagger$ & & \\
\hline Father present $<$ once per week & 1.65 & $1.17-2.32$ & 0.03 \\
\hline \multicolumn{4}{|l|}{ Daytime carer of child } \\
\hline Not the mother & 1.00 & & \\
\hline Mother & 0.77 & $0.33-1.34$ & 0.13 \\
\hline \multicolumn{4}{|l|}{ Mother's education } \\
\hline$<5$ years & $1.00 \dagger$ & & \\
\hline$>5$ years & 0.62 & $0.42-0.91$ & 0.02 \\
\hline \multicolumn{4}{|l|}{ House made of traditional material } \\
\hline No & 1.00 & & \\
\hline Yes & 1.33 & $0.81-4.14$ & 0.02 \\
\hline \multicolumn{4}{|l|}{ Distance from health clinic } \\
\hline$<1 \mathrm{~h}$ & $1.00 \dagger$ & & \\
\hline$>1 \mathrm{~h}$ & 1.80 & $1.13-2.89$ & $<0.001$ \\
\hline \multicolumn{4}{|l|}{ Presence of toilet } \\
\hline Yes & 1.00 & & \\
\hline No & 1.46 & $1.02-2.08$ & 0.02 \\
\hline \multicolumn{4}{|l|}{ Breast-fed last child } \\
\hline No & 1.00 & & \\
\hline Yes & 0.49 & $0.25-0.95$ & $<0.001$ \\
\hline \multicolumn{4}{|l|}{ Birth weight } \\
\hline$>2500 \mathrm{~g}$ & $1.00 \ddagger$ & & \\
\hline$<2500 \mathrm{~g}$ & 5.25 & $3.10-8.87$ & $<0.001$ \\
\hline
\end{tabular}

high-energy groundnut biscuits $\left(4.3 \mathrm{MJ} \mathrm{day}^{-1}\right.$ ) for about 20 weeks before delivery in Gambia had a 40\% reduced risk of having a low-birth-weight baby compared with controls ${ }^{16}$.

There are three major ways by which foetal growth may be affected by infection in the mother. First, the mother herself may be subjected to a series of infections which influence her own nutrition, making supplies of nutrients less available to the foetus; second, the placenta may not transfer nutrients satisfactorily as a result of a variety of disease conditions; and third, the foetus itself may be infected, such that growth and development are impaired. Prevention of IUGR requires programmes that focus on all three areas. An antenatal survey in the district found over $50 \%$ of pregnant women presenting at antenatal clinics to have a sexually transmitted infection ${ }^{17}$. HIV is an increasing problem in this area, with a prevalence of $24 \%$ during the survey. The impact this has on the incidence of low birth weight needs to be investigated further. Interventions must therefore also be directed to the mother as well as the child.

Local qualitative studies have documented the dual responsibility of childcare and trying to attain food security that local women face ${ }^{18}$. This is especially acute in households where there is no father present. The heavy physical burdens of fetching water and firewood and agricultural work, coupled with the lack of time for rest and short birth intervals, place a heavy nutritional stress on women. Interventions that assist women through the availability of appropriate technology ${ }^{19}$, financial assistance $^{20}$, childcare facilities ${ }^{21}$ and increased accessibility to health care ${ }^{22}$ could also have beneficial effects for the nutritional status of children. Leslie ${ }^{23}$ also pointed out that these strategies should aim to empower women and thus increase their ability to secure increased family resources for child nutrition. It has consistently been shown that households where women have greater control of the income spend a greater proportion of their income on child welfare.

Children from households with toilets were significantly less likely to be UWFA, even after controlling for socioeconomic factors. Daniels et $a l^{24}$ found that the safe disposal of faeces reduced diarrhoea incidence by $36 \%$ in Lesotho. They concluded that this has greater impact than the provision of improved water quality. A significant number of households do not have toilets or access to clean water; this has a double negative effect by increasing women's workload and increasing the chances of diarrhoeal infections.

In keeping with other studies ${ }^{25,26}$, maternal education was found to be associated with childhood undernutrition even after controlling for other socio-economic factors. In this setting, an effect was only seen amongst those mothers who had at least 5 years of schooling. This suggests that there is the potential for improving the educational content of the first few years by making it more relevant to health needs.

The 'valley of death' which children in poor communities enter during the weaning period of $6-18$ 
months is shown quite clearly in Fig. 2. The startling fall-off in growth is thought to occur as a result of the introduction of solid foods into the diet which are deficient in energy and micronutrients, coupled with an increased number of infections ${ }^{13}$. In this population breast-feeding is strongly associated with better nutritional status. Even though breast-feeding is still widespread, it is less than in other rural areas in South Africa ${ }^{4}$ and a majority of children were given supplementary fluids and food before 4 months of age. A significant minority of carers also either decreased or stopped feeding children after an illness. Further qualitative studies are needed to understand the reasons for these behaviours and to develop appropriate nutrition communication strategies.

Importantly, those who live the furthest from the health clinic are at increased risk of stunting even after controlling for other risk factors. This complements the results of a study in a neighbouring district, which found that children who did not attend the clinic were twice as likely to be stunted ${ }^{10}$. Primary healthcare clinics need to increase their accessibility to the poor and clinic-based interventions need to be complemented by communitybased programmes that reach the most vulnerable.

Selection bias could have resulted from the sampling frame being restricted to just those areas with CHWs. These areas could be better off since they have organised to apply for a CHW, thus leading to an underestimate of the poverty and nutritional status of children in the whole district. However, the study sites were situated in all parts of the district and all households with pre-school children in the CHW area were measured. The number of femaleheaded households, level of female education, predominance of migratory labour and remittances for income, low number of toilets, lack of clean water supply, prevalence of breast-feeding and anthropometric status of the children are all very similar to the findings of a recent national survey ${ }^{4}$.

\section{Conclusion}

This study has attempted to delineate risk factors for undernutrition within a broader ecological framework. While there are individual health and feeding behaviours that need to be addressed, it has also uncovered the maternal and socio-economic factors which present an array of constraints in the social environment shaping the infant feeding and caring practices employed by women. For the full potential of nutrition promotion activities to be realised, there is a need to address some of these 'deeper' constraints. Further research is required to elucidate the coping mechanisms of poor women and interventions that can strengthen them. It is clear that undernutrition cannot be viewed solely as an infant health problem. Improving the quality of health care to women and children remains an important task but this needs to be complemented by broader, multi-sector community-based programmes.

\section{References}

1 Pelletier DL, Frongillo EA Jr, Schroeder DG, Habicht JP. The effects of malnutrition on child mortality in developing countries. Bulletin of the World Health Organization 1995; 73(4): 443-8.

2 Hunt JM. Reversing productivity losses from iron deficiency: the economic case. Journal of Nutrition 2002; 132(Suppl. 4): 794S-801S.

3 Brown J, Pollit E. Malnutrition, poverty and intellectual development. Scientific American 1996 2: 38-43.

4 Labadarios D., ed. The National Food Consumption Survey (NFCS): Children Aged 1-9 years, South Africa, 2001. Pretoria: National Department of Health, 2002.

5 Marshall CA. An evaluation of aspects of the PEM scheme for malnourished children in Guateng Province, 1995. South African Journal of Food Science and Nutrition 1996; 8(Suppl. 2): S11.

6 McCoy D. Evaluation of the South African Primary School Nutrition Programme. Durban: Health Systems Trust, 1998.

7 Sanders D. Success factors in community-based nutrition programmes. Food and Nutrition Bulletin 1999; 20(3): 307-14.

8 National Center for Health Statistics, Center for Disease Control. NCHS Growth Curves for Children Birth-18 years. Washington, DC: US Government Printing Office, 1978.

9 Victora CG, Huttly SR, Fuchs SC, Olinto TA. The role of conceptual frameworks in epidemiological analysis: a hierarchical approach. International Journal of Epidemiology 1997; 26: 224-7.

10 Solarsh GC, Sanders D, Gibson C, Gouws E. Community based surveillance vs. sentinel site sampling in determining the nutritional state of children. South African Medical Journal 1994; 84: 747-52.

11 SALDRU/World Bank. Report of Situational Analysis in South Africa. Cape Town: University of Cape Town Press, 1994.

12 Waterlow JS. Reflections on stunting. In: Gopolan C, ed. Recent Trends in Nutrition. Delhi: Oxford University Press, 1993.

13 Keller W. The epidemiology of stunting. In: Waterlow JC, ed. Linear Growth Retardation in Less Developed Countries. Vevey/New York: Nestle Nutrition/Raven Press, 1988.

14 de Onis M, Blössner M, Villar J. Levels and patterns of intrauterine growth retardation in developing countries. European Journal of Clinical Nutrition 1998; 52(Suppl. 1): S5-15.

15 Kramer M. Balanced protein/energy supplementation in pregnancy. Cochrane Review 1999. Oxford: Update Software.

16 Ceesay SM, Prentice AM, Cole TJ, Foord F, Weaver LT, Poskitt EM, et al. Effects on birth weight and perinatal mortality of maternal dietary supplements in rural Gambia: 5 year randomised controlled trial. British Medical Journal 1997; 315: 786-90.

17 Wilkinson D, Abdool Karim SS, Harrison A, Lurie M, Colvin M, Connolly C, et al. Unrecognized sexually transmitted infections in rural South African women: a hidden epidemic. Bulletin of the World Health Organization 1999; 77(1): 22-8.

18 Chopra M, Ross F. Causes of Malnutrition in a Rural Community: A Qualitative Study. Report to South African Participatory Poverty Analysis. Pretoria: World Bank, 1996.

19 Kennedy E. Approaches to linking agriculture and nutrition programmes. Health Policy and Planning 1994; 9(3): 294-305.

20 Quanine J. Women and nutrition: Grameen Bank experience. In: Women and Nutrition. ACC/SCN State of the Art Series, Nutrition Policy Discussion Paper No 6. Geneva: World Health Organization, 1990. 
21 Shah PM, Walimbe SR, Dhole VS. Wage earning mothers, mother substitutes and the care of young children in rural Maharashtra. Indian Paediatrics 1979; 16(2): 167-73.

22 Mata L. The Santa Maria Canque study: health and survival of Mayan Indians under deprivation, Guatemala. In: Scrimshaw NS, ed. Community-based Longitudinal Nutrition and Health Studies. Boston, MA: International Foundation for Developing Countries, 1995.

23 Leslie J. Women's nutrition: the key to improving family health in developing countries. Health Policy and Planning 1991; 6: 1-19.
24 Daniels DL, Cousens SN, Makoae LN, Feachem RG A case-control study of the impact of improved sanitation on diarrhoea morbidity in Lesotho. Bulletin of the World Health Organization 1990; 68(4): 455-63.

25 Vella V, Tomkins A, Nviku J, Marshall T. Determinants of nutritional status in south-west Uganda. Journal of Tropical Pediatics 1995; 41: 89-98.

26 Ricci JA, Becker S. Risk factors for wasting and stunting among children in Metro Cebu, Philippines. American Journal of Clinical Nutrition 1996; 63: 966-75. 